\title{
Acute retinal necrosis as a novel complication of chickenpox in adults
}

Department of Okayama University Medical School, Okayama City, Japan T Matsuo

M Koyama

N Matsuo

Correspondence to:

Toshihiko Matsuo, MD, Department of

Ophthalmology, Okayama University Medical

School, 2-5-1 Shikata-cho, Okayama City, Okayama 700, Japan.

Accepted for publication 4 January 1990
T Matsuo, M Koyama, N Matsuo retinal arteritides coupled with uveal inflammation (iridocyclitis). If untreated, it results in permanent visual reduction or loss. ${ }^{2+}$ It is caused by infection with varicella zoster or herpes simplex type 1 virus. ${ }^{56}$ We report hereon three immunocompromised adult patients who developed acute retinal necrosis about three weeks after the onset of chickenpox.

\section{Case reports}

CASE I

A 26-year-old woman in the tenth month of gestation experienced redness and blurred vision in the right eye about one month after the onset of chickenpox. The best corrected visual acuity was 20/200 in the right eye and 20/30 in the left. The intraocular pressure was $10 \mathrm{mmHg}$ in both eyes. She showed confluent yellowish white retinal exudates in the peripheral fundus of both eyes coupled with iridocyclitis: $3+$ keratic precipitates. $3+$ aqueous cells, $2+$ vitreous cells in the right eye, and $1+$ keratic precipitates, $2+$ aqueous cells, $1+$ vitreous cells in the left eye. A healthy baby, the patient's second child, was delivered by uncomplicated caesarean operation two weeks later. Immediately afterwards intravenous administration of acyclovir $500 \mathrm{mg} / \mathrm{day}$ for two weeks and prednisolone tapered from $200 \mathrm{mg} /$ day was started. The fundus lesion resulted in retinochoroidal degeneration in the following three weeks, and the visual acuity in both eyes returned to 20/20.

\section{CASE 2}

A 20-year-old woman noticed redness in the right eye about three weeks after the onset of severe chickenpox. She had been taking $20 \mathrm{mg} /$ day of prednisolone for severe nephrotic syndrome during the preceding three years. The best corrected visual acuity was 20/20 in both eyes, and the intraocular pressure was 18 $\mathrm{mmHg}$ in both eyes. Examination disclosed a necrotic retinal area limited to the peripheral fundus in the right eye (Fig 1), which was associated with anterior segment inflammation as $1+$ keratic precipitates, $2+$ aqueous cells, and $2+$ vitreous cells. The left eye appeared normal. She received a drip infusion of acyclovir $1500 \mathrm{mg} /$ day for two weeks and prednisolone tapered from $200 \mathrm{mg} /$ day. The necrotic lesion resolved within three weeks.

CASE 3

A 29-year-old man developed severe chickenpox during admission to hospital for bronchiectasis. He noticed blurred vision and floating spots in
Figure 1: Fluorescein angiogram in the right eye of case 2. Note avascular necrotic area limited to peripheral retina. 


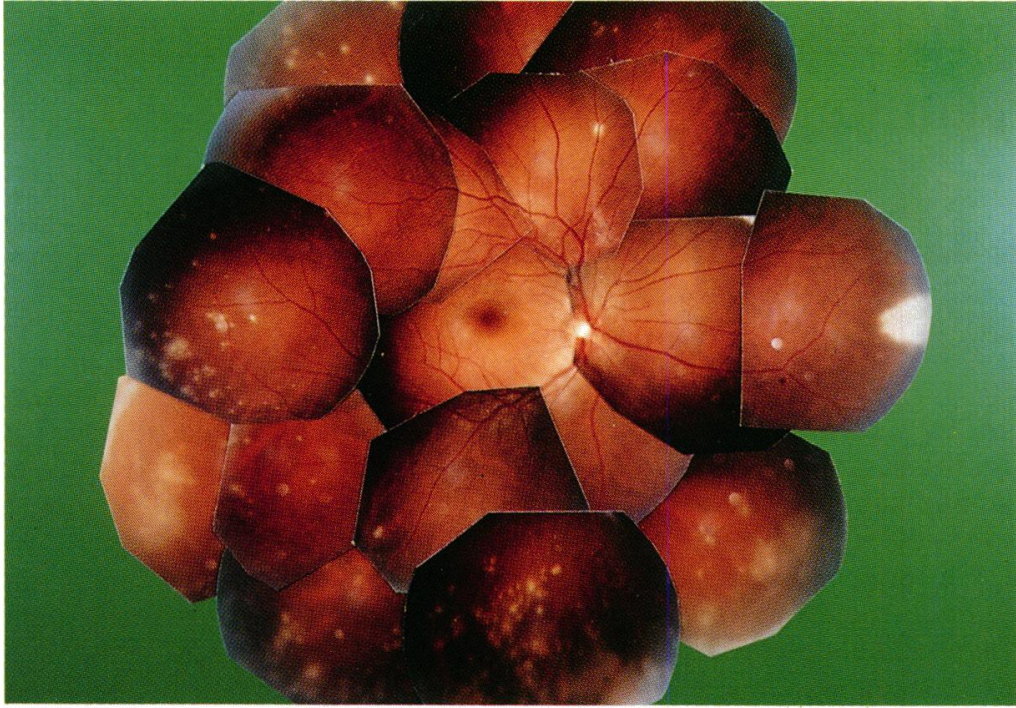

Figure 2A

Figure 2: Fundus photographs of the right eye of case 3. A: On initial visit. B: One week later. Note necrotic retinal lesions extending in one week.

the right eye 20 days after the onset of chickenpox. The best corrected visual acuity was 20/15 in both eyes, and the intraocular pressure was 15 $\mathrm{mmHg}$ in both eyes. The fundus in the right eye showed a typical picture of acute retinal necrosis (Fig 2A), together with iridocylitis: $1+$ keratic precipitates, $3+$ aqueous cells, and $1+$ vitreous cells. The left eye was normal. He received a drip infusion of acyclovir $1500 \mathrm{mg} /$ day for two weeks and gradual tapering of prednisolone from 200 $\mathrm{mg} / \mathrm{day}$. The necrotic lesion of the retina extended gradually (Fig 2B), but finally resolved in three weeks. Two years previously he had undergone left orchidectomy and radiation for testicular seminoma, Subsequently he was prone to bronchitis and low grade fever.

\section{Discussion}

All three patients were in their $20 \mathrm{~s}$ and in a

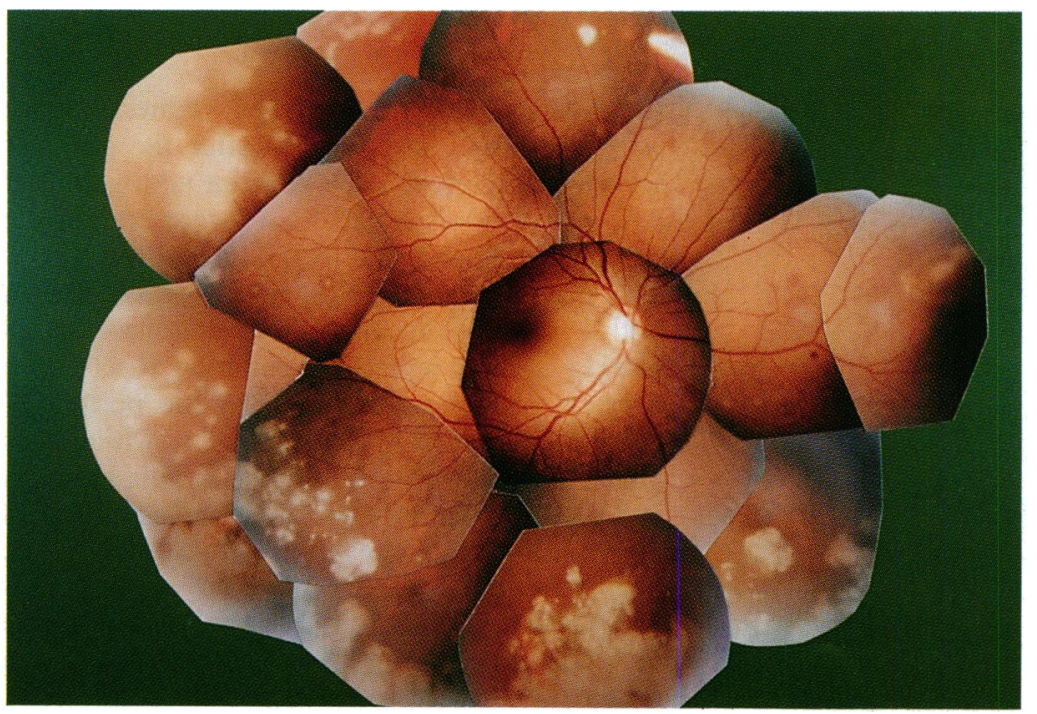

Figure 2B somewhat immunocompromised state: the woman in case 1 was in the tenth month of gestation, the woman in case 2 had been taking steroids for three years, and the man in case $3 \mathrm{had}$ had repeated episodes of bronchitis and low grade fever after successful treatment for testicular seminoma. All three patients had severe chickenpox which resolved without complications but developed acute retinal necrosis about three weeks to one month after the onset of the chickenpox. Initial symptoms of acute retinal necrosis were blurred vision, floating spots, and/or redness. Both eyes were involved in one patient, but only one eye in the others.

Acute retinal necrosis is classified clinically into fulminant and mild types as we proposed recently. ' Isolated retinal necrotic lesions occurring initially in the peripheral fundus become confluent and extend rapidly to the posterior pole in the fulminant type, leading to marked visual reduction, in spite of intensive treatment with acyclovir and cortiosteroid. In contrast patients with the mild type of acute retinal necrosis showed slowly progressive, but self limiting necrotic lesions of the retina and preserved good vision with the drug therapy. All these three patients showed the mild type of acute retinal necrosis following chickenpox and regained good visual acuity after the intraocular inflammation had subsided. As we discussed in the recent report, ${ }^{7}$ administration of acyclovir and steroid seems to reduce the rate of its late complications, such as retinal tears. Thus it is important to detect acute retinal necrosis, regardless of mild or fulminant type, as early as possible and to start appropriate therapy. Acute retinal necrosis should be kept in mind as a possible complication when patients with chickenpox complain of eye symptoms.

It is interesting to note that the period from the onset of chickenpox to acute retinal necrosis was about three weeks in all three patients. Thus the chickenpox had subsided when the acute retinal necrosis began. Herpes group virus has been found electron microscopically in the retina with acute retinal necrosis obtained by biopsy. ${ }^{45}$ In immunocompromised patients varicella-zoster virus would tend to be more easily reactivated in the retina, leading to acute retinal necrosis.

1 Ray CG. Chickenpox (varicella) and herpes zoster. In: Petersdorf RG, Adams RD, Braunwald E, Isselbacher KJ Martin JB, Wilson JB, eds. Harrison's principles of interna medicine. 10th ed. New York: McGraw-Hill, 1983: 1121-5.

2 Urayama A, Yamada N, Sasaki T, et al. Unilateral acute uveiti with retinal periarteritis and detachment. $\mathcal{F p n} \mathcal{f}$ Clin Ophthalmol 1971; 25: 607-19.

3 Willerson D, Aaberg TM, Reeser FH. Necrotizing vasoocclusive retinitis. Am f Ophthalmol 1977; 84: 209-19.

4 Young NJA, Bird AC. Bilateral acute retinal necrosis. $\mathrm{Br} \mathcal{F}$ Ophthalmol 1978; 62: 581-90.

5 Culbertson WW, Blumenkranz MS, Haines H, Gass JDM Mitchell KB, Norton EWD. The acute retinal necrosis Mitchell KB, Norton EWD. The acute retinal necrosis
syndrome. 2. Histopathology and etiology. Ophthalmology syndrome. 2. Hist

6 Freeman WR, Thomas EL, Rao NA, et al. Demonstration of herpes group virus in acute retinal necrosis syndrome.Am $\hat{f}$ Ophthalmol 1986; 102: 701-9.

7 Matsuo T, Nakayama T, Koyama T, Koyama M, Matsuo N. A proposed mild type of acute retinal necrosis syndrome. Am $\mathcal{F}$
Ophthalmol 1988; 105: 579-83. 